\title{
Lead editorial -
}

\section{Atrial fibrillation and stroke risk}

\section{Professor Gregory YH Lip}

Professor of Cardiovascular Medicine, University of Birmingham Centre for Cardiovascular Sciences, City Hospital, Birmingham, UK

\section{Drugs in Context}

DOI: http://dx.doi.org/I0.7573/dic.212239

Citation: Lip GYH. Lead editorial - Atrial fibrillation and stroke risk. Drugs in Context: e212239. doi:10.7573/dic.212239

Copyright: this is an open access article published under the terms of the Creative Commons License Deed (CC BY-NC-ND 3.0) which allows you to share, copy, distribute and transmit the work provided it is properly attributed. You may not use this work for commercial purposes. For further information on commercial use, contact publisher@justmedicalmedia.com or go to www.drugsincontext.com/copyright.

NB: This article was originally published by Just Medical Media Ltd in Drugs in Context 201 I:6:I-4. This edition of Drugs in Context was funded by Boehringer Ingelheim Ltd who reviewed it for accuracy. 


\title{
Lead editorial -
}

\section{Atrial fibrillation and stroke risk}

\author{
Professor Gregory Y H Lip
}

\author{
Professor of Cardiovascular Medicine, University of Birmingham Centre for Cardiovascular Sciences, \\ City Hospital, Birmingham, UK
}

Atrial fibrillation (AF) is the commonest sustained cardiac rhythm disorder, and has attracted much attention due to its association with an increased mortality and morbidity from stroke and thromboembolism. Importantly, there is an effective treatment for stroke prevention in AF, i.e. oral anticoagulation, that reduces the risk of stroke by two-thirds. ${ }^{1}$

Until fairly recently, the only way of administering such thromboprophylaxis was by the use of vitamin K antagonists, such as warfarin. Unfortunately, warfarin use is associated with important lifestyle limitations, including possible interactions with certain drugs (e.g. antibiotics, anticonvulsants) and diet (e.g. green vegetables), as well as the need for alcohol restriction and International Normalised Ratio (INR) monitoring so as to ensure that patients keep within a therapeutic INR range of 2.0-3.0. ${ }^{2}$ Given the significant interand intra-patient variability in INR, many clinicians and patients do not like using warfarin, and given its disutility, efforts have been directed towards identifying patients with AF who are at highest risk, and would benefit most from warfarin thromboprophylaxis. In patients who refuse warfarin, or have had 'failed' warfarin therapy due to difficulties in attending for anticoagulation monitoring or an inability to keep safely within the target INR range, many guidelines have recommended the use of antiplatelet therapy. ${ }^{3}$ Also, there was the perception that aspirin was an alternative to warfarin but there is now clear evidence that aspirin is inferior to warfarin for stroke prevention, and the rates of major bleeding (or intracranial haemorrhage) may not be much different between aspirin and warfarin, especially in the elderly. ${ }^{4}$

Whilst AF is said to increase the risk of stroke fivefold, this risk is not homogeneous. Indeed, the risk of stroke is influenced by the presence or absence of various stroke risk factors, which cumulatively add to an increasing risk of stroke. Many of these risk factors have been derived from non-warfarin arms of trial cohorts, as well as from some epidemiological cohort studies. However, trial cohorts - especially those pertaining to the historical trials done nearly two decades ago - had variable degrees of recording and definitions of stroke risk factors, and thus, for some stroke risk factors, additional information needs to be obtained from epidemiological or cohort studies. ${ }^{5}$
In the Stroke in Atrial Fibrillation Working Group systematic review, the most consistent stroke risk factors are prior stroke or transient ischaemic attack (TIA) (which increases risk 2.0-fold), whilst age increases stroke risk 1.5 -fold per decade. ${ }^{6}$ Indeed, the risk of stroke rises from age 65 upwards, and as patients with $\mathrm{AF}$ get older, the absolute benefit of oral anticoagulation increases, and the absolute benefit of antiplatelet therapy declines. ${ }^{7}$ The benefits are even greater at the endpoint of vascular events, but for serious bleeding, there is a small increase with increasing age, and marginally more so with warfarin or antiplatelet therapy.

Diabetes and hypertension increase the risk of stroke 1.8-fold and 2.0-fold, respectively - but a history of heart failure was not a significant predictor of stroke in $\mathrm{AF}^{6}$ In contrast, the presence of moderate-to-severe systolic impairment is clearly an independent stroke risk factor, and this may be a reflection of the many patients labelled as being in 'heart failure' who do not actually have systolic impairment, and the risk of stroke with so-called 'diastolic dysfunction' is undefined. Female gender increases the risk of stroke 1.6-fold, whilst vascular disease is associated with a high risk of cardiovascular events in AF (including stroke), and previous myocardial infarction and complex aortic plaque on the descending aorta revealed on transoesophageal echocardiography are associated with stroke in AF. ${ }^{6,8}$

The stroke risk factors mentioned above have been used to formulate stroke risk stratification schema, and some have categorised patients into low, moderate and high stroke risk strata. This division is an artificial one, since stroke risk is a continuum, and the predictive value of classification into these artificial strata is modest. Given the availability of new oral anticoagulants that overcome the disutility of warfarin, ${ }^{2}$ and the recognition that aspirin is an inferior choice (and not much safer), the focus has been directed towards improving the identification of the 'truly low risk' AF patients who need no antithrombotic therapy, whilst patients with one or more stroke risk factors should be considered for oral anticoagulation. ${ }^{5}$

The most commonly used and simple stroke risk stratification scheme is the $\mathrm{CHADS}_{2}$ [Cardiac failure, Hypertension, Age, Diabetes, Stroke (Doubled)] score, 
Table I. Risk factors for stroke and thromboembolism in non-valvular AF.

$\begin{array}{ll}\text { 'Major' risk factors } & \text { 'Clinically relevant non-major' risk factors } \\ \text { Previous stroke, TIA or systemic embolism } & \text { Heart failure or moderate-to-severe LV systolic dysfunction (e.g. LV EF } \leq 40 \%) \\ \text { Age } \geq 75 \text { years } & \text { Hypertension - Diabetes mellitus } \\ & \text { Female sex - Age 65-74 years } \\ & \text { Vascular disease* }\end{array}$

Risk factor-based approach expressed as a point-based scoring system, with the acronym $\mathrm{CHA}_{2} \mathrm{DS}_{2}$-VASc (Note: Maximum score is 9 since age may contribute 0,1 or 2 points)

\section{Risk factor}

Score

Congestive heart failure/LV dysfunction

Hypertension

Age $\geq 75$

I

Diabetes mellitus

Stroke/TIA/thromboembolism

Vascular disease*

Age 65-74

Sex category (i.e. female sex)

Maximum score

Risk category

$\mathrm{CHA}_{2} \mathrm{DS}_{2}$-VASc score

$\geq 2$

non-major' risk factors

One 'clinically relevant non-major' risk factor

No risk factors

*Myocardial infarction, peripheral artery disease, complex aortic plaque.
I

I

2

I

I

9

Figure I. Clinical flowchart for the use of oral anticoagulation for stroke prevention in AF.

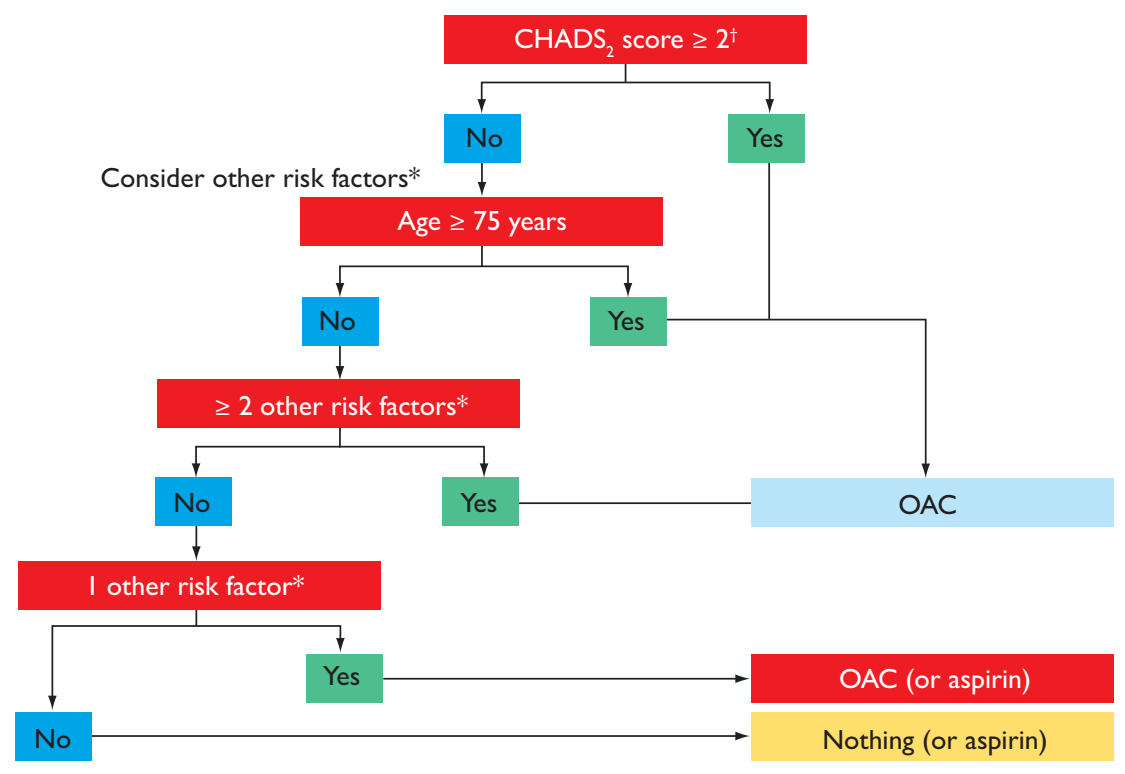

${ }^{\dagger}$ Congestive heart failure, hypertension, age $\geq 75$ years, diabetes, stroke/TIA/thromboembolism (doubled).

*Other clinically relevant non-major risk factors: age 65-74, female sex, vascular disease. 
which has been validated in multiple cohorts following initial derivation from an amalgamation of the Stroke Prevention in Atrial Fibrillation 1 study (SPAF1) and the AF Investigators' schema, and tested in the NonRheumatic AF cohort, which was a hospitalised cohort study. ${ }^{9}$ However, the $\mathrm{CHADS}_{2}$ score has been noted for not including many stroke risk factors, and in the original validation, a $\mathrm{CHADS}_{2}$ score of 0 was 'low risk', whilst a score of 1-2 was 'intermediate or high risk' and a score of $>2$ was 'high risk'. ${ }^{10}$ With such a classification, the $\mathrm{CHADS}_{2}$ score categorises nearly 60-65\% of patients with AF as at 'moderate risk' where older guidelines recommend giving 'warfarin or aspirin' when it is not clear that even 'moderate risk' subjects (or even those with a $\mathrm{CHADS}_{2}$ score of 1 ) would benefit from warfarin rather than aspirin. ${ }^{11}$

Thus, to be more inclusive - rather than exclusive of stroke risk factors, the $\mathrm{CHA}_{2} \mathrm{DS}_{2}$-VASc score has been proposed, to complement the $\mathrm{CHADS}_{2}$ score. $^{12}$ In the new 2010 European Society of Cardiology (ESC) guidelines on AF management, ${ }^{13}$ the artificial categorisation into low, moderate and high risk strata is de-emphasised and a risk factor-based approach is recommended. The ESC guidelines define stroke risk factors as 'major' and 'clinically relevant non-major' (Table 1). The initial stroke assessment (Figure 1) should start with the $\mathrm{CHADS}_{2}$ score, where a score of $\geq 2$ necessitates oral anticoagulation therapy. If the $\mathrm{CHADS}_{2}$ score is $0-1$, then other risk factors should be considered - if the patient is aged $\geq 75$ years or if two 'clinically relevant non-major' risk factors are present (i.e. a $\mathrm{CHA}_{2} \mathrm{DS}_{2}$-VASc score of $\geq 2$ ), then oral anticoagulation is recommended. Where one 'clinically relevant non-major' risk factor is present (i.e. a $\mathrm{CHA}_{2} \mathrm{DS}_{2}$-VASc score of 1 ), then patient values and preferences need to be considered, and if the patient values stroke prevention then oral anticoagulation is the preferred option. Those with a $\mathrm{CHA}_{2} \mathrm{DS}_{2}$-VASc score of 0 are 'truly low risk' and can be managed with no antithrombotic therapy.

In summary, stroke risk assessment has evolved to become more inclusive of stroke risk factors, and to improve on the identification of the truly low-risk patient with AF who does not need antithrombotic therapy. All other patients with one or more stroke risk factors should be considered for thromboprophylaxis, preferably with oral anticoagulation therapy.

\section{Address correspondence to:}

Professor GYH Lip

Centre for Cardiovascular Sciences

City Hospital

Birmingham

B18 7QH, UK

Email:g.y.h.lip@bham.ac.uk

\section{Competing interests:}

Professor GYH Lip was clinical adviser to the UK NICE Guidelines on AF management and a Task Force member of the 2010 ESC guidelines and ACCP9 writing committee. He has received funding for research, educational symposia, consultancy and lecturing from different manufacturers of drugs used for the treatment of $\mathrm{AF}$ and thrombosis.

\section{References}

1. Lip GY, Lim HS. Atrial fibrillation and stroke prevention. Lancet Neurol 2007;6(11):981-93.

2. Ahrens I, Lip GY, Peter K. New oral anticoagulant drugs in cardiovascular disease. Thromb Haemost 2010;104:49-60.

3. Fuster V, Rydén LE, Cannom DS et al. ACC/ AHA/ESC 2006 Guidelines for the management of patients with atrial fibrillation: a report of the American College of Cardiology/American Heart Association Task Force on practice guidelines and the European Society of Cardiology Committee for Practice Guidelines (writing committee to revise the 2001 guidelines for the management of patients with atrial fibrillation): developed in collaboration with the European Heart Rhythm Association and the Heart Rhythm Society. Circulation 2006;114(7):e257-e354.

4. Mant J, Hobbs FD, Fletcher K et al. on behalf of the BAFTA investigators. Midland Research Practices Network (MidReC). Warfarin versus aspirin for stroke prevention in an elderly community population with atrial fibrillation (the Birmingham Atrial Fibrillation Treatment of the Aged Study (BAFTA)): a randomised controlled trial. Lancet 2007;370:493-503.

5. Lip GY, Halperin JL. Improving stroke risk stratification in atrial fibrillation. Am J Med 2010;123:484-8.

6. Stroke Risk in Atrial Fibrillation Working Group. Independent predictors of stroke in patients with atrial fibrillation: a systematic review. Neurology 2007;69:546-54.

7. van Walraven C, Hart RG, Singer DE et al. Oral anticoagulants $v$ s aspirin in nonvalvular atrial fibrillation: an individual patient meta-analysis. JAMA 2002;288(19):2441-8.

8. Hughes M, Lip GY on behalf of the Guideline Development Group. National Clinical Guideline for Management of Atrial Fibrillation in Primary and Secondary Care, National Institute for Health and Clinical Excellence. Stroke and thromboembolism in atrial fibrillation: a systematic review of stroke risk factors, risk stratification schema and cost effectiveness data. Thromb Haemost 2008;99:295-304.

9. Gage BF, Waterman AD, Shannon W, Boechler M, Rich MW, Rudford MJ. Validation of clinical 
classification schemes for predicting stroke: results from the National Registry of Atrial Fibrillation. JAMA 2001;285:2864-70.

10. Karthikeyan G, Eikelboom JW. The CHADS score for stroke risk stratification in atrial fibrillation friend or foe? Thromb Haemost 2010;104:45-8.

11. Gorin L, Fauchier L, Nonin E et al. Antithrombotic treatment and the risk of death and stroke in patients with atrial fibrillation and a CHADS2 score $=1$. Thromb Haemost 2010;103(4):833-40.

12. Lip G, Nieuwlaat R, Pisters R, Lane DA, Crijns HJ. Refining clinical risk stratification for predicting stroke and thromboembolism in atrial fibrillation using a novel risk factor based approach: the euro heart survey on atrial fibrillation. Chest 2010;137:263-72.

13. Camm AJ, Kirchhof P, Lip GY et al. on behalf of the European Heart Rhythm Association. European Association for Cardio-Thoracic Surgery guidelines for the management of atrial fibrillation: the Task Force for the Management of Atrial Fibrillation of the European Society of Cardiology (ESC). Europace 2010;12(10):1360-420. 